\title{
Planejamento e proposta de Unidade Didática para ensino de tradução: usos do dicionário*
}

\section{Design and proposal of a Teaching Unit for translation teaching (training translators): The uses of the dictionary}

\author{
Mariana Francis \\ Adja Balbino de Amorim Barbieri Durão ${ }^{* *}$ \\ Maria Lúcia Vasconcellos ${ }^{* * *}$
}

Resumo: Esta proposta insere-se no ramo aplicado dos Estudos da Tradução e objetiva trazer à discussão a experiência de elaboração de uma Unidade Didática (UD) para ensino de tradução, especificamente no que se refere ao desenvolvimento da subcompetência instrumental na utilização de dicionários. Com base em fundamentos teórico-metodológicos da Didática da Tradução (conforme proposta pelo Grupo PACTE, Universidad Autónoma de Barcelona, Espanha) e também por estudiosos da Lexicografia Pedagógica (WELKER [2004], BEVILACQUA [2006] e KRIEGER [2006]), estipulou-se uma UD com a finalidade de alcançar uma série de objetivos

\footnotetext{
" No presente estudo expõem-se as bases teóricas, os procedimentos e os resultados provenientes da realização de uma atividade solicitada para a disciplina Didática da Tradução do curso de Pós-graduação em Estudos da Tradução (PGET) da Universidade Federal de Santa Catarina (UFSC), em nível de doutorado. 0 presente artigo foi escrito em coautoria, incluindo a doutoranda, sua orientadora e a ministrante da disciplina.

"* UNIOESTE / PG-UFSC. marianafrancis@gmail.com

${ }^{* * *}$ PGET-UFSC. adjabalbino@gmail.com

PGET-UFSC. marialuciabv@gmail.com
} 
Francis, M.; DuRão, A. B. De A. B.; VAsconcellos, M. L. - Planejamento e proposta de Unidade Didática para o ensino de tradução: usos do dicionário

pedagógicos sobre o tema em pauta, objetivos esses relacionados ao emprego produtivo de dicionários no que se refere à elaboração de traduções, mediante a programação de tarefas de tradução aplicáveis ao ensino de tradução em cursos de graduação.

Palavras-chave: Didática da tradução; PACTE; competência tradutória; subcompetência instrumental; dicionários

Abstract: This proposal is located in the applied branch of Translation Studies and aims at sharing and discussing the experience of designing a Teaching Unit (TU) for Translation teaching, particularly in what refers to the acquisition of the instrumental subcompetence regarding the use of dictionaries. Drawing upon theoretical and methodological frameworks of Translation Didactics (Grup PACTE, Universidad Autónoma de Barcelona, Spain) and of Pedagogical Lexicography (WELKER [2004], BEVILACQUA [2006] and KRIEGER [2006]) the paper presents a Teaching Unit (TU) designed to achieve a series of learning objectives related to the effective use of dictionaries by translators in carrying out the translation activity. Based on translation tasks, around which TUs are structured, a pedagogical proposal is put forward which is applicable to translation teaching in undergraduate courses.

Keywords: Translation didactics; PACTE; translation competence; instrumental subcompetence; dictionaries

\section{Introdução}

A pesquisa cognitiva sobre a Competência Tradutória (CT) (PACTE, http://grupsderecerca.uab.cat/pacte/en) vem provocando mudanças em direção à orientação para o processo, perspectivas cognitivo-construtivistas e concepção integradora de desenho curricular no ensino de tradução: professores de tradução e formadores desses professores estão cada vez mais preocupados com a observação criteriosa e crítica de suas próprias práticas de ensino em sintonia com esse novo paradigma, particularmente no que tange ao design de material didático (cf. Kelly 2005: cap. 8). 
Francis, M.; DuRÃo, A. B. DE A. B.; VAsconcellos, M. L. - Planejamento e proposta de Unidade Didática para o ensino de tradução: usos do dicionário

Esse cenário emergente impõe uma série de desafios no que diz respeito ao desenho de objetivos de aprendizagem, e a partir daí, de um programa curricular integrador em que todos os aspectos do currículo derivem de objetivos de aprendizagem planejados para os cursos e estejam intimamente relacionados a eles (cf. KeLLY 2005: cap. 2).

Nesse contexto, e explorando a interface entre os Estudos da Tradução (em seu ramo aplicado referente à Didática da Tradução) e a Lexicografia Pedagógica, este trabalho tem por objetivo compartilhar o planejamento e a elaboração de uma Unidade Didática (UD) para ensino da tradução, aplicável em cursos de graduação. No caso específico aqui descrito, a UD contempla as línguas portuguesa e espanhola e foi planejada com vistas ao desenvolvimento da subcompetência instrumental (conforme modelo de Competência Tradutória/CT proposto pelo Grupo PACTE - Processo de Aquisição da Competência Tradutória e Avaliação) no que se refere à utilização de documentação para fins tradutórios, especificamente os dicionários.

Inicialmente, considera-se relevante explicitar, ainda que de forma sintética, alguns dos conceitos teóricos adotados neste estudo, os quais serviram para determinar os passos e os procedimentos adotados na elaboração da UD. Na sequência, segue a descrição das ações executadas na construção da UD com a explicitação de seus objetivos, sua estrutura e os materiais que a compõem. No processo de criação e recriação de cada tarefa não se perdeu de vista a reflexão sobre o experimento realizado, exposta nos comentários finais, a modo de conclusão.

\section{Algumas considerações teóricas}

Como já se vinha indicando, as bases teóricas que deram sustentação a esta proposta provêm de duas áreas do conhecimento estreitamente 
Francis, M.; DuRão, A. B. DE A. B.; VAsconcellos, M. L. - Planejamento e proposta de Unidade Didática para o ensino de tradução: usos do dicionário

vinculadas: os Estudos da Tradução e a Lexicografia. Como os objetivos da UD estão voltados para o ensino, será preciso lançar mão também de alguns conceitos provenientes de duas subáreas atreladas às temáticas pedagógicas: Didática da Tradução e Lexicografia Pedagógica.

\subsection{A Didática da Tradução}

No que concerne à Didática da Tradução, na formação de tradutores merece destaque especial a concepção de Competência Tradutória (CT) proposta por Hurtado Albir (1999 e 2005). Nas palavras dessa autora, "A competência tradutória é um conhecimento especializado, integrado por um conjunto de conhecimentos e habilidades que singulariza o tradutor e o diferencia de outros falantes bilíngues não tradutores" (HURTADO ALBIR 2005: 19). Essa concepção de CT foi proposta pelo PACTE, um grupo de pesquisa consolidado da Universidad Autónoma de Barcelona (UAB) - Espanha. Os interesses fundamentais da pesquisa desenvolvida pelo PACTE são a pesquisa empírico-experimental sobre a Competência Tradutora (CT) e sua aquisição em tradução escrita, o desenho curricular na formação de tradutores, o uso da metodologia empírica e experimental em tradutologia e o uso das tecnologias da informação e da comunicação (TICs) aplicadas na pesquisa em tradução.

Segundo Hurtado Albir e Alves (2009: 63), a CT é a competência que subjaz ao trabalho do tradutor/intérprete e o habilita para realizar as operações cognitivas necessárias para o adequado desenrolar do processo tradutório. 0 modelo de CT do PACTE propõe o desenvolvimento de cinco subcompetências (bilíngue, extralinguística, instrumental, conhecimento sobre tradução e conhecimento estratégico), associadas a componentes psicofisiológicos (cf. HURTADO AlBiR; ALves 2009: 66). O modelo é apresentado abaixo mediante o seguinte esquema: 
Francis, M.; Durão, A. B. De A. B.; VAsconcellos, M. L. - Planejamento e proposta de Unidade Didática para o ensino de tradução: usos do dicionário

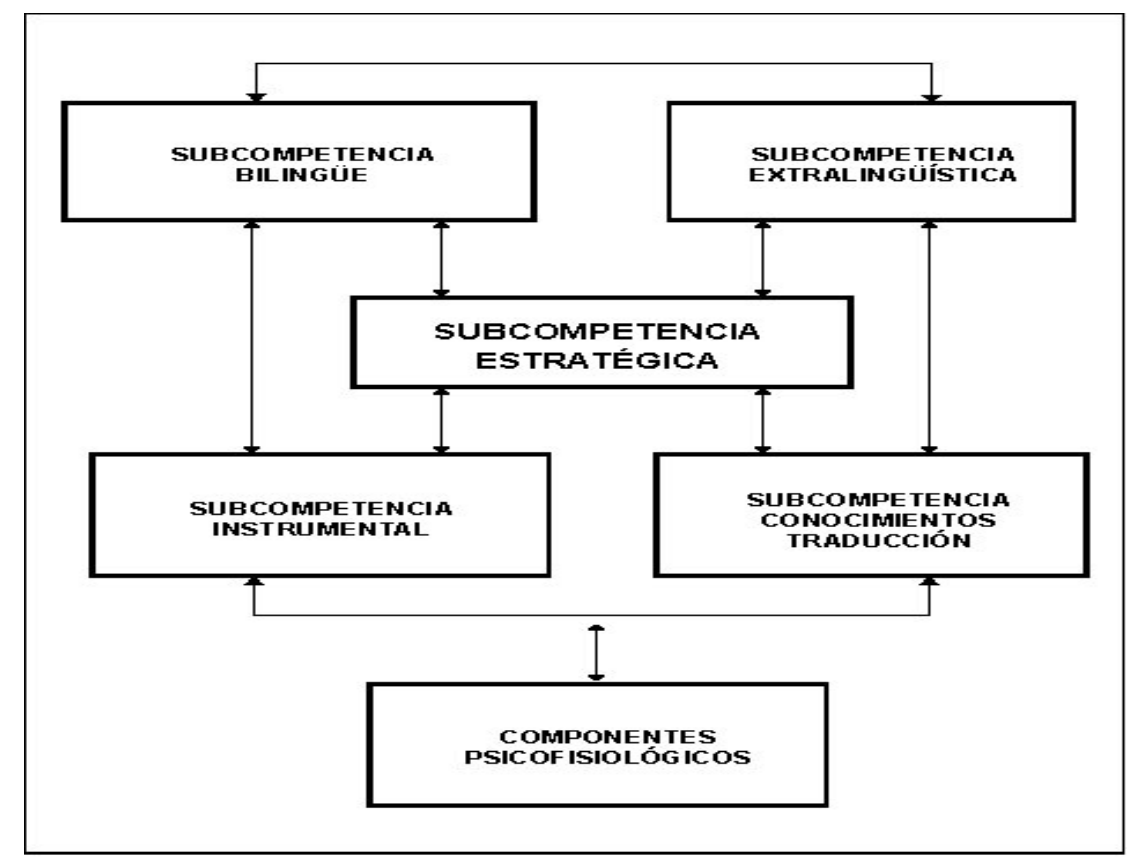

Figura 2- A Competência Tradutória (CT) segundo o modelo holístico de PACTE (HURTADO ALBIR 2005: 28).

Esse modelo tem impacto direto na formação de tradutores, uma vez que, essencialmente, a Didática de Tradução objetiva o desenvolvimento de práticas pedagógicas que tenham a finalidade de levar os tradutores-emformação à aquisição da CT. Hurtado Albir (2007: 176) argumenta em favor da interação de dois eixos que, a seu ver, devem fazer parte do processo de formação de tradutores, a saber, o quadro teórico dos Estudos da Tradução (que abarca o conceito de tradução, o conceito de CT e a aquisição de CT) e o quadro teórico pedagógico de teorias de aprendizagem e de ensino (incluindo a teoria de aprendizagem cognitivo-construtivista, teoria de ensino que inclui o currículo aberto e integrado).

No presente estudo, optou-se por dar destaque, especificamente, à questão do desenvolvimento da subcompetência instrumental que consiste, segundo o grupo PACTE (2003: 59), no conhecimento, predominantemente 
Francis, M.; DuRão, A. B. De A. B.; VAsconcellos, M. L. - Planejamento e proposta de Unidade Didática para o ensino de tradução: usos do dicionário

processual, que habilita para a escolha e o emprego de fontes documentais, dentre as quais, encontram-se os dicionários.

Um dos eixos fundamentais para o desenvolvimento da competência tradutória, assim como de suas subcompetências, em nível pedagógico, é o enfoque por tarefas de tradução, o qual está pautado numa abordagem cognitivo-construtivista da aprendizagem.

Cabe salientar ainda, com relação às abordagens para o ensino de tradução, alguns princípios do socioconstrutivismo adotados para a elaboração da UD, da qual este artigo trata. Nessa perspectiva de formação de tradutores, segundo Kiraly (2000: 60), as atividades pedagógicas devem se aproximar da realidade do tradutor, advogando em favor de atividades didáticas que se assemelhem a projetos de tradução autênticos.

Considerar a perspectiva socioconstrutivista de aprendizagem da tradução, segundo Kiraly (2000: 66), implica em assumir a importância da interação entre os indivíduos envolvidos no contexto de sala de aula e dos diversos pontos de vista que os alunos tenham em relação ao conhecimento em construção. Em cada momento, ao se depararem com diferentes visões, os aprendizes poderão avaliar as vantagens e as desvantagens de algumas soluções encontradas para os problemas propostos e terão a oportunidade de escolher aquelas que considerarem mais adequadas. Nesse contexto, 0 professor deve atuar como mediador dos conhecimentos, sem assumir para si a incômoda postura de dono da palavra final.

Levando-se em conta esse quadro teórico, torna-se possível planejar objetivos e conteúdos e abordar o ensino/aprendizagem de tradução a partir de uma abordagem por tarefa-de-tradução, proposta por Hurtado Albir (1999). A tarefa-de-tradução foi definida como "unidade de trabalho na aula, representativa da prática tradutória, dirigida intencionalmente para a aprendizagem da tradução e desenhada com um objetivo concreto, uma 
Francis, M.; DuRÃo, A. B. DE A. B.; VAsconcellos, M. L. - Planejamento e proposta de Unidade Didática para o ensino de tradução: usos do dicionário

estrutura e uma sequência de trabalho"” (HURTADo ALBIR 1999: 56, tradução nossa).

Segundo esclareceu Hurtado Albir (1999: 50), “a unidade didática configura-se como um conjunto de tarefas encaminhadas à consecução dos objetivos escolhidos"2 (tradução nossa) programadas de forma sequencial pelos professores, com a participação dos aprendizes.

Essa concepção de tarefa-de-tradução vincula as atividades desenvolvidas em cada UD à aquisição de uma subcompetência da CT, contribuindo para o estabelecimento de uma nova definição para os objetivos da aprendizagem baseados em competências. Nesse contexto, a tarefa de tradução torna-se o eixo ao redor do qual uma UD é construída e é capaz de dotar o desenho curricular de um caráter globalizante, integrando todos os elementos: objetivos, conteúdos, metodologia e avaliação (HURTADo ALBIR 2005: 42).

Hurtado Albir, editora da série 'Aprender a Traducir' (2015, Guía Didáctica), esclarece que sua proposta pedagógica de formação de tradutores tem como base uma perspectiva cognitivo-construtivista de aprendizagem, na linha pedagógica de formação por competências. Nessa linha, o aluno protagoniza e ocupa o centro do que ela chama de processo guiado de descobrimento, com vistas à aquisição de sua competência tradutória (CT).

Segundo essa autora, no âmbito de tal processo guiado e gradual, a aquisição da CT se dá gradualmente, de forma ativa e heurística no contexto de um desenho didático concebido como um conjunto de tarefas de tradução (HURTADo ALBIR 1999) propondo, então, a tarefa de tradução como unidade organizadora do processo de aprendizagem.

\footnotetext{
1 unidad de trabajo en el aula, representativa de la práctica traductora, que se dirige intencionalmente al aprendiz de la traducción y que está diseñada con un objetivo concreto, una estructura y una secuencia de trabajo.

${ }^{2}$ La unidad didáctica queda configurada como un conjunto de tareas encaminadas a la consecución de los objetivos elegidos.
} 
Francis, M.; DuRão, A. B. DE A. B.; VAsconcellos, M. L. - Planejamento e proposta de Unidade Didática para o ensino de tradução: usos do dicionário

A tarefa-de-tradução constitui-se como eixo principal em torno do qual é elaborada a Unidade Didática (UD) - unidade pedagógica da formação do tradutor, recurso central em sua aquisição da competência tradutória. Assim, o desenho de um curso consiste em uma sequenciação de tarefas de tradução organizadas em Unidades Didáticas, sendo a UD a estrutura que possibilita e favorece a aquisição da CT, por meio de tarefas de aprendizagem, tarefas de integração e tarefas integradoras, em busca de uma maior integração de competências e uma maior autonomia do aluno.

Assim, a UD se relaciona diretamente à aquisição da CT por meio das tarefas de tradução, que, segundo Hurtado Albir (2015: 13), permitem criar situações relacionadas com a vida profissional do tradutor por meio de realização de tarefas autênticas, proporcionam uma metodologia ativa ao oferecer ao aluno atividades nas quais ele aprende realizando tarefas de tradução, permitindo, desse modo, a prática de uma pedagogia centrada nos processos que o aluno precisa ativar para resolver uma tradução. Finalmente, essa proposta tende a levar o aluno a participar ativamente do processo de aquisição da competência tradutória, como protagonista do ato didático, e o professor passa a exercer o papel de guia e facilitador.

A proposta deste artigo inspira-se nas considerações aqui relatadas, buscando contribuir para o desenvolvimento da subcompetência instrumental do aluno, no que tange às estratégias de uso de dicionários como um dos recursos auxiliares disponíveis à tradução. Argumenta-se que, por meio da UD, estruturada em torno das tarefas de tradução, é possível auxiliar o aluno a desenvolver habilidades de consulta aos dicionários. No modelo proposto o uso dessas habilidades constitui, como já se disse, parte da subcompetência instrumental, componente da CT. 
Francis, M.; DurÃo, A. B. De A. B.; Vasconcellos, M. L. - Planejamento e proposta de Unidade Didática para o ensino de tradução: usos do dicionário

\subsection{A Lexicografia Pedagógica}

Neste trabalho, propõe-se a elaboração de uma UD cujo foco é o desenvolvimento da subcompetência instrumental, especificamente no que diz respeito ao uso de dicionários como apoio para o bom andamento de uma tarefa tradutória. Assim, entende-se ser necessária a explicitação de alguns conceitos teóricos da Lexicografia Pedagógica, subárea da Lexicografia centrada na reflexão sobre dicionários, no tocante a tipologias, estrutura e funcionalidade do dicionário como gênero textual, suas finalidades, estratégias para a sua escolha e sobre seu uso como instrumento de apoio em traduções. Essas considerações envolvem, também, aspectos sobre o ensino de línguas.

No que se refere às características e tipologia dos dicionários, em virtude dos objetivos da UD incluírem uma aproximação e um reconhecimento estrutural dessas obras, deve-se destacar que

a obra dicionarística não se resume a uma listagem, mas, como um texto, possui regras próprias de organização. Nessa regularidade organizacional, há projetos específicos definidos em conformidade com os fins visados pelo lexicógrafo [...] [e, por sua vez,] há grandes diferenças tipológicas, em razão dos objetivos de cada um [dos dicionários], das necessidades dos usuários previstos, da amplitude do repertório léxico, da escolha das informações registradas, entre outros aspectos (KRIEGER 2006: 142-143).

Estudiosos da Lexicografia Pedagógica, como Welker (2004: 77-182) e Bevilacqua (2006: 109-133), entre outros, observam que, de modo geral, os dicionários compõem-se de três partes: macroestrutura, microestrutura e textos externos. Identificar os elementos que compõem o dicionário, em especial, as informações microestruturais e suas finalidades específicas, contribui para dinamizar a sua consulta, propiciando agilidade e êxito na busca de dados. 
Francis, M.; DuRão, A. B. DE A. B.; VAsconcellos, M. L. - Planejamento e proposta de Unidade Didática para o ensino de tradução: usos do dicionário

No que diz respeito à escolha e uso de dicionários, alguns autores, entre os quais estão Duran e Xatara (2007) e Werner (2005), referem-se à importância de disciplinas voltadas para a didática dos dicionários, pois tanto a escolha quanto o uso metódico e criterioso de obras lexicográficas outorgam benefícios ao consulente, levando-o a adquirir autonomia e destreza para desenvolver eficazmente essas atividades.

Para avaliar a eficácia dos dicionários em determinado tipo de situação ou circunstância de uso (WELKER 2006: 14-16), como, por exemplo, a tradução de textos, pode ser de grande valia uma análise mediante protocolos de uso. Segundo Welker (2006: 28) "Fazer um protocolo de uso de dicionários significa anotar por escrito ou descrever oralmente como o consulente procede e, às vezes, por que faz a consulta". Essa é uma das tarefas propostas na UD com o objetivo de que o aluno desenvolva estratégias que the permitam avaliar criticamente os dicionários, assim como utilizá-los de forma metódica.

As opções teóricas referentes aos dois campos do conhecimento antes referidos, ou seja, a Didática da Tradução e a Lexicografia Pedagógica, objetivam o desenvolvimento da competência tradutória no que se refere ao uso de documentação básica, assim como visam promover a autonomia do aluno quanto ao próprio processo de aprendizagem.

\section{O passo a passo na construção da UD: Métodos e procedimentos adotados}

A escolha da temática abordada na UD foi motivada, por um lado, pela formação e atuação profissional de duas das autoras deste artigo em assuntos que envolvem a Lexicografia. Por outro lado, o tema ampara-se na necessidade de desenvolver a subcompetência instrumental profissional 
Francis, M.; DuRÃo, A. B. DE A. B.; VAsconcellos, M. L. - Planejamento e proposta de Unidade Didática para o ensino de tradução: usos do dicionário

durante o processo de formação de tradutores, sendo que um dos objetivos de desenvolver essa subcompetência é "preparar [o aprendiz] para saber identificar, para valorar a fiabilidade e para utilizar as diferentes fontes de documentação na tradução e na interpretação"3 (KELLY 2002: 17, tradução nossa).

Expondo exemplos que auxiliam na elaboração de UDs, Hurtado Albir (1999: 56) propõe que "as unidades didáticas estão elaboradas em torno a um objetivo específico (ou intermediário) buscando, em cada caso, uma tarefa final" (tradução nossa). Tomando tal proposta como diretriz, pautou-se a programação da UD de forma que os alunos alcancem três objetivos gerais:

(1) conhecer obras de referência, especialmente diferentes tipos de dicionários, identificando, de forma global, seus elementos estruturais e funcionais e sua utilidade como ferramentas auxiliares de tradução;

(2) adquirir estratégias para avaliar e escolher dicionários adequados para cada objetivo;

(3) adquirir estratégias de uso de dicionários em situações específicas de tradução.

O desenho geral da UD, ou seja, o esquema sobre o qual a proposta foi desenvolvida, também teve como modelo os exemplos disponibilizados por Hurtado Albir (1999: 75-78) em sua metodologia de trabalho. Esses exemplos exploram especificamente a documentação básica e a utilização de documentação, tendo como eixo direcionador o enfoque por tarefas de tradução. A proposta foi adaptada para poder atender aos objetivos préestabelecidos, ou seja, às metas da UD. Segundo Hurtado Albir (1999: 50) “o

\footnotetext{
${ }^{3}$ Preparar [el aprendiz] para saber identificar, valorar la fiabilidad y utilizar las diferentes fuentes de documentación para la traducción y la interpretación.

${ }^{4}$ Las unidades didácticas están elaboradas en torno a un objetivo específico (o intermedio) y persiguen en cada caso una tarea final.
} 
Francis, M.; DuRão, A. B. DE A. B.; VAsconcellos, M. L. - Planejamento e proposta de Unidade Didática para o ensino de tradução: usos do dicionário

enfoque por tarefas supõe um marco flexível, integrador da metodologia e dos objetivos, que convêm adaptar para cada situação educativa" ${ }^{5}$ (tradução nossa).

A mudança mais representativa em relação aos exemplos consistiu em dividir a proposta em duas partes, sendo uma delas a versão do aluno e a outra a versão do professor, a fim de que cada uma dessas partes atendesse especificamente às necessidades de um e outro participante do processo pedagógico. A versão do aluno contém as tarefas e orientações gerais para sua realização. A versão do professor oferece um passo a passo que direciona como se deve proceder para que a UD seja executada.

Em busca de atingir os objetivos propostos, a estrutura da UD foi organizada em torno de quatro tarefas, as quais estão diretamente relacionadas aos objetivos propostos para a UD, e que foram assim denominadas:

(1) Tarefa 1 - Estruturas e usos de dicionários;

(2) Tarefa 2 - Critérios para a escolha de dicionários;

(3) Tarefa 3 - Estratégias para o uso de dicionários em traduções;

(4) Tarefa final - Uso de dicionários na tradução direta (espanholportuguês).

Cada uma dessas tarefas apresenta, no início, um material de apoio, isto é, comentários, informações e esclarecimentos que servem para que os aprendizes adentrem na temática, a modo de introdução. Na sequência, propõem-se fichas com as atividades a serem desenvolvidas pelos alunos, sendo que, para cada uma delas, oferecem-se, antepostas, as instruções correspondentes.

\footnotetext{
${ }^{5}$ El Enfoque por tareas supone, pues, un marco flexible, integrador de la metodología y de los objetivos, que conviene adaptar a cada situación educativa.
} 
Francis, M.; DuRÃo, A. B. DE A. B.; VAsconcellos, M. L. - Planejamento e proposta de Unidade Didática para o ensino de tradução: usos do dicionário

Levando em consideração aspectos socioconstrutivistas segundo os quais é de grande importância propiciar um espaço público de debate no qual os alunos envolvidos na atividade possam se manifestar e analisar diversos pontos de vista (KIRALY 2000: 66), cada tarefa prevê momentos em que essa troca é possível, inclusive, permitindo a comparação das respostas de cada participante ou no debate sobre aspectos derivados da realização das tarefas propostas.

Apresentam-se, a seguir, os procedimentos adotados na elaboração de cada tarefa, a fim de expor o planejamento e a elaboração dessa UD.

\subsection{Tarefa 1 - Estruturas e usos de dicionários}

O objetivo desta tarefa é que o aluno reflita sobre o uso intuitivo e o uso reflexivo (aprendizagem formal) de dicionários e, ao mesmo tempo, reconheça os elementos estruturais e funcionais desse gênero textual.

A tarefa consta de um material de apoio e de três fichas de trabalho assim denominadas:

(1) Ficha 1. Âmbito de aprendizagem;

(2) Ficha 2. Comparação das respostas;

(3) Ficha 3. Características do gênero textual dicionário".

A Ficha 1 é uma enquete e serve para chamar a atenção do aluno sobre os dicionários que já usou, identificando o contexto no qual obteve informações sobre como utilizá-los (aprendizagem formal ou informal) e, também, aqueles com os quais ainda não trabalhou. Na Ficha 2 há uma comparação das respostas de cada aluno, com o objetivo de gerar um debate sobre dicionários que não thes são conhecidos, os mais utilizados e, ainda, sobre a falta de disciplinas que se ocupem da didática dos dicionários nas 
Francis, M.; DuRão, A. B. DE A. B.; VAsconcellos, M. L. - Planejamento e proposta de Unidade Didática para o ensino de tradução: usos do dicionário

diferentes etapas educacionais. Na Figura 2, exposta a seguir, apresentam-se o material de apoio para essa tarefa e as duas primeiras fichas de trabalho.

\section{Tarefa 1: ESTRUTURAS E USOS DE DICIONÁRIOS}

Material de apoio: Estruturas e usos de dicionários
Nas traduções, os dicionários são obras de consulta necessárias para facilitar o conhecimento ou para recordar
informações sobre as línguas (no caso dos bilíngues, informações contrastivas). Assim como muitos tradutores
aprenderam a traduzir traduzindo, é comum que os usuários de dicionários nunca tenham recebido orientações
técnicas sobre seu uso, ou seja, aprenderam a usar os dicionários usando-os. A fim de agilizar a consulta aos dicionários
e dinamizar o processo tradutório faz-se necessária, durante a formação profissional, uma aproximação ao gênero
textual 'dicionário' o que propiciará uma compreensão de sua vasta diversidade, assim como de suas possibilidades de
uso para diferentes finalidades. Nesse sentido é preciso, inicialmente:
1. Identificar o âmbito em que as informações sobre os diferentes dicionários foram obtidas;
2. Reconhecer características próprias do gênero textual 'dicionário';
3. Reconhecer a utilidade de informações lexicográficas de diferentes obras para diversas finalidades tradutórias.

\begin{tabular}{|l|l|l|l|l|} 
& Uso intuitivo & Aprendizagem formal & Aprendizagem informal & Nunca usei \\
\hline 1. Monolíngues g. & & & & \\
\hline 2. Bilíngues g. & & & & \\
\hline 3. Fraseológicos & & & & \\
\hline 4. Analógicos & & & & \\
\hline $\begin{array}{l}\text { 5. De sinônimos, } \\
\text { antônimos e parônimos }\end{array}$ & & & & \\
\hline $\begin{array}{l}\text { 6. Terminológicos } \\
\text { (diatópicos) }\end{array}$ & & & & \\
\hline $\begin{array}{l}\text { 8. Visuais } \\
\text { 9. Outro. Qual? }\end{array}$ & & & & \\
\hline $\begin{array}{l}\text { PONTUAÇÃonistas } \\
\text { (somatória por colunas) }\end{array}$ & & & & \\
\hline
\end{tabular}

TradTerm, São Paulo, v. 26, Dezembro/2015, pp. 315-343

www.usp.br/tradterm 
Francis, M.; Durão, A. B. de A. B.; VAsconcellos, M. L. - Planejamento e proposta de Unidade Didática para o ensino de tradução: usos do dicionário

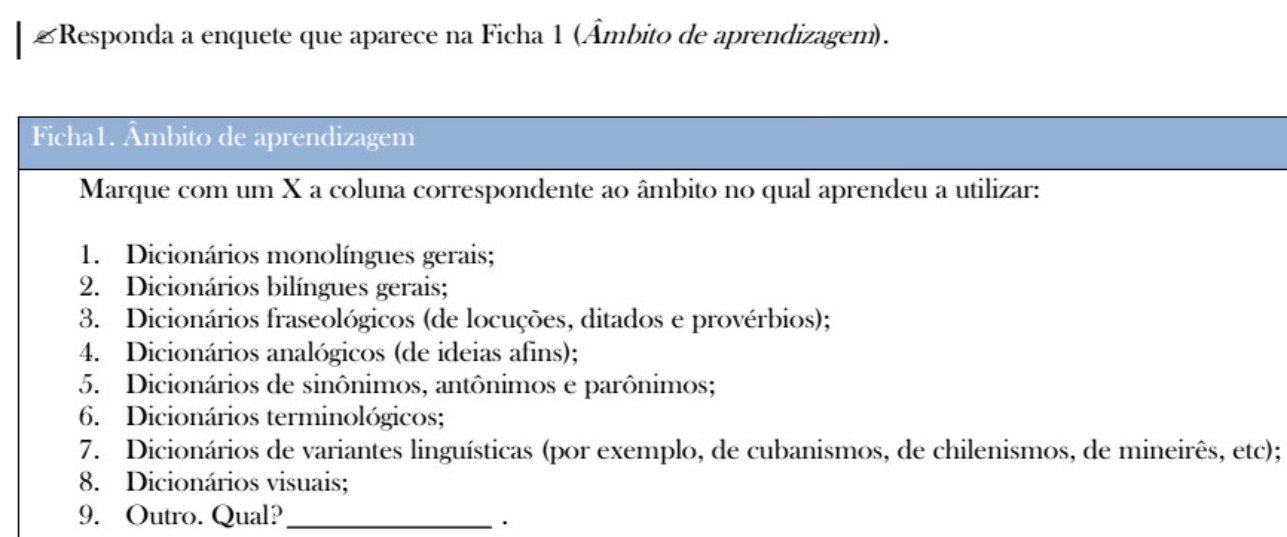

Obs.: Aprendizagem formal refere-se, por exemplo, a contextos tais como a escola e a universidade, ou seja, instituições de ensino em geral; aprendizagem informal, por outro lado, refere-se ao processo que acontece fora de instituições de ensino (por exemplo, quando pais, colegas ou conhecidos ensinam algo).

$\Varangle$ Compare suas respostas com as dos seus colegas, completando a Ficha 2 (Comparação das respostas).

\begin{tabular}{|c|c|c|c|c|}
\hline \multicolumn{5}{|c|}{ Ficha 2. Comparaçào das respostas } \\
\hline & Uso intuitivo & Aprendizagem formal & Aprendizagem informal & Nunca usei \\
\hline \multicolumn{5}{|l|}{ Pontuações individuais } \\
\hline RESULTADO & & & & \\
\hline
\end{tabular}

Figura 3 - Material de apoio, Ficha 1 e Ficha 2 da Tarefa 1. UD Usos do dicionário (de nossa autoria).

A Ficha 3 inicia com a apresentação de informações prévias sobre as estruturas, as funções e as finalidades de diferentes tipos de dicionários e, na sequência, há três verbetes retirados de diferentes dicionários: Michaelis (2008: 436), Sargentim (n/d: 16-17) e Real Academia Española (n/d). Em cada um desses verbetes, o aluno deverá ser capaz de reconhecer elementos que compõem sua microestrutura e suas finalidades. Para exemplificar essa tarefa, na Figura 3 apresentam-se as informações prévias, as instruções e o primeiro verbete a ser analisado pelos aprendizes. 
Francis, M.; DuRão, A. B. DE A. B.; VAsconcellos, M. L. - Planejamento e proposta de Unidade Didática para o ensino de tradução: usos do dicionário

Fiecha 3. Caracteristicas do gênero textual "dicionári "

\section{Informaç̋̃es prévias}

A rigor, todo dicionário compõe-se de três partes: 1) macroestrutura (conjunto de lemas, ou unidades léxicas, para as quais se oferecem diversas informações); 2) microestrutura (conjunto de informações oferecidas para cada lema); e 3) textos externos (informações adicionais como, por exemplo: instruções de uso, listas de abreviaturas e siglas, entre outros). Por sua vez, a microestrutura pode conter: classe(s) gramatical(ais), gênero(s), definições, equivalente(s), sinônimo(s), antônimo(s), parônimo(s), exemplos de uso, marcas de uso, explicações contrastivas, imagens, entre outras informaçòes.

Até meados do século $\mathrm{XX}$, os dicionários, normalmente, eram apenas objetos de erudição, por isso quase nunca havia a preocupação de elaborar obras específicas para atender a públicos diferentes. Os dicionários, nessa época, quase sempre eram compilados de forma intuitiva. Com o surgimento da Lexicografia Pedagógica, passou a ser desejável que os dicionários partam de projetos lexicográficos claros, que proponham informaçòes sistemáticas e que sejam elaborados para tipos determinados de consulentes, isto é, que busquem atender necessidades de um público alvo pré-estabelecido. Os dicionários deixaram de ser pensados como objetos para 'colecionar' palavras, e passaram a ser vistos como instrumentos com diversas 'finalidades'.

Em virtude da composição estrutural dos verbetes de cada dicionário, algumas de suas finalidades podem ser identificadas, como, por exemplo: diferenciar acepções (significados) na $\mathrm{LM}^{*}$ (ou na $\mathrm{LE}^{\star \star}$ ); auxiliar a fixação da sintaxe; auxiliar a tradução (oral e/ou escrita) para uma LE; auxiliar a compreensão (oral ou escrita) de uma LE; minimizar o uso de repetiçòes; esclarecer usos (na LM ou na LE); prevenir erros (por exemplo, os derivados de falsas semelhanças entre as línguas); dinamizar a consulta de temas específicos concentrando as informações por campos semânticos (assuntos) na LM e/ou na LE.

*LM= Língua Materna

${ }^{\star *} \mathrm{LE}=$ Língua Estrangeira

Com base nas informações anteriores, identifique os elementos microestruturais dos verbetes, refletindo e anotando qual a finalidade dos mesmos (se possível, em relação a atividades tradutórias).

$$
\begin{aligned}
& \text { a.ga.sa.Ihar [agaza } \lambda \text { 'ar] vtd+vpr } 1 \text { Ampa- } \\
& \text { rar, acoger, albergar, hospedar. } 2 \text { Abrigar. } \\
& \text { quem pratica esqui tem de se agasalhar } \\
& \text { muito bem para não ficar gripado / quie- } \\
& \text { nes practican esquí tienen que abrigarse } \\
& \text { muy bien para no pegarse una gripe. } \\
& \text { Em espanhol, agasajar significa "re- } \\
& \text { cepcionar, receber bem, homenagear": } o \\
& \text { embaixador recepcionou seus convidados } \\
& \text { / el embajador agasajó a sus invitados. }
\end{aligned}
$$

A) Elementos da microestrutura:

Finalidades:

(MichaElis 2008: 436)

Figura 4 - Ficha 3 da Tarefa 1. UD Usos do dicionário (de nossa autoria).

No desenvolvimento da UD, o professor, utilizando as informações do material de apoio, deverá explicar aos alunos a diferença entre o uso intuitivo e o uso sistematizado (por aprendizagem) de dicionários, assim como alertar sobre a grande diversidade de obras lexicográficas existentes e sua utilidade para múltiplas finalidades, dentre elas, a tradutória. Deverá, também, explicar aos alunos que o objetivo dessa tarefa é promover uma aproximação ao gênero textual dicionário, identificando e ampliando os conhecimentos que tenha sobre as tipologias e a funcionalidade aplicada à tradução. 
Francis, M.; DuRÃo, A. B. DE A. B.; VAsconcellos, M. L. - Planejamento e proposta de Unidade Didática para o ensino de tradução: usos do dicionário

$\mathrm{Na}$ sequência, cada aluno responderá à enquete da Ficha 1 (Âmbito de aprendizagem) e depois, lerá suas respostas para preencher o quadro subsequente na Ficha 2 (Comparação das respostas). Os alunos compararão suas respostas e poderão debater, brevemente, sobre o assunto. 0 professor poderá apresentar alguns exemplares de diferentes tipos de dicionários propiciando o contato direto dos alunos com essas obras.

Para introduzir informações sobre as estruturas e finalidades dos dicionários, o professor deve orientar os aprendizes a lerem as Informações prévias, no início da Ficha 3 (Características do gênero textual dicionário) e incentivá-los para que apontem outros dados lexicográficos que os diferentes dicionários oferecem e sobre a sua utilidade para fins de tradução. $\mathrm{Na}$ sequência, cada aluno preencherá a Ficha 3. A seguir, o professor pedirá aos alunos que leiam as suas respostas, reunindo os resultados alcançados por cada aluno e expondo-os a todos os participantes e, também, promovendo um debate sobre esses resultados.

A avaliação dessa tarefa será realizada mediante o preenchimento das fichas pelos alunos e sua participação oral no debate.

\subsection{Tarefa 2 - Critérios para a escolha de dicionários}

A finalidade dessa tarefa é que o aluno adquira estratégias que the permitam avaliar e escolher dicionários, prestando atenção a critérios de seleção baseados numa análise metódica das estruturas lexicográficas de cada obra.

Essa tarefa compõe-se de:

(1) Material de apoio;

(2) Ficha 4. Análise de verbetes para a escolha de dicionários. 
Francis, M.; DuRão, A. B. DE A. B.; VAsconcellos, M. L. - Planejamento e proposta de Unidade Didática para o ensino de tradução: usos do dicionário

A Ficha 4 possui informações prévias, que consistem em orientações adicionais para a realização da tarefa, e alguns esclarecimentos sobre a presença de falsos amigos nos dicionários bilíngues (DB) e sua relevância para a tradução. A ficha apresenta, também: os verbetes de três dicionários para três lemas, ou entradas, que correspondem a falsos amigos do português em relação ao espanhol (adiantar, aliás e apurar); três frases que contém as palavras correspondentes a esses lemas, as quais o aluno deverá traduzir para o espanhol; espaços para que o aluno avalie se as informações presentes no dicionários foram úteis para a tradução (em cada verbete); e um questionário final para que o aluno faça uma síntese do experimento. Para maior clareza, na Figura 4 expõe-se o Material de apoio da Tarefa 2, as orientações para o preenchimento da Ficha 4 e uma amostra da tarefa solicitada.

Tarefa 2: CRITÉRIOS PARA A ESCOLHA DE DICIONÁRIOS

Material de apoio: Critérios para a escolha de dicionários

Vários pesquisadores indicam que a maioria dos usuários de dicionários escolhe uma determinada obra de consulta observando apenas: o renome da editora que o publicou, seu preço, a qualidade da encadernação, o fato de ter sido indicado por professores de línguas, o número dos verbetes que possui. No entanto, outros critérios, como, por exemplo, a relevância para as necessidades do usuário, a quantidade e a qualidade de informações oferecidas para cada lema e a sistematização dessas informações raramente são analisados. Uma escolha ponderada demanda a análise metódica das estruturas lexicográficas de cada obra, em especial suas informações microestruturais. 
Francis, M.; Durão, A. B. de A. B.; VAsconcellos, M. L. - Planejamento e proposta de Unidade Didática para o ensino de tradução: usos do dicionário

e Leia as 'Informações prévias' da Ficha 4. (Análise de verbetes para a escolha de dicionários) e compare as informações lexicográficas expostas em diferentes dicionários para os mesmos lemas. Após, preencha a ficha identificando quais dessas informações foram úteis para a tradução (dentro dos contextos) das palavras destacadas em cada frase. Por último, responda às perguntas.

\begin{tabular}{|c|c|c|}
\hline \multicolumn{3}{|c|}{$\begin{array}{l}\text { Cada uma das frases propostas nessa ficha contém um falso amigo (ou falso cognato) para o par de línguas português- } \\
\text { espanhol: adiantar, aliás e apurar. As frases são: A) Ficar nervoso não vai adiantar; é melhor manter a calma; B) Eles } \\
\text { moram na Rua Marechal Floriano..., aliás, Marechal Deodoro; C) As votações já terminaram; agora vão apurar os votos. } \\
\text { Falsos amigos são considerados pontos opacos para a compreensão e produção de textos em uma LE. Bons dicionários } \\
\text { se caracterizam por dar relevância a esses elementos das línguas, a fim de minimizar erros e facilitar sua tradução. } \\
\text { Analise, de forma contrastiva, os verbetes de } 3 \text { dicionários para cada um dos falsos amigos. }\end{array}$} \\
\hline Dicionário 1 (D1) & Dicionário 2 (D2) & Dicionário 3 (D3) \\
\hline $\begin{array}{l}\text { adiantar vt \& vi adelantar; não adianta } \\
\text { nada! ino sirve de nada! } \\
\text { Јadiantar-se vp adelantarse. }\end{array}$ & $\begin{array}{l}\text { a.di.an.tar [adiãa'tar] vtd +vpr 1 Adelantar, } \\
\text { mover hacia adelante. } 2 \text { Acelerar, apresu- } \\
\text { rar. vti } 3 \text { Aventajar a alguien. }\end{array}$ & $\begin{array}{l}\text { adiantar v.t. 1. Adelantar, mover hacia ade- } \\
\text { lante. 2. Avanzar, adelantar, progresar. } \\
\text { Adiantar o serviço. Avanzar con el trabajo. } \\
\text { 3. Adelantar, anticipar (pagamento). 4. Col. } \\
\text { Servir, tener utilidad, valer. Não adianta } \\
\text { chorar. De nada sirve llorar. v.p. 5. Ade- } \\
\text { lantarse. 6. Anticiparse. }\end{array}$ \\
\hline
\end{tabular}

$$
(\ldots)
$$

Preencha a ficha

A) Ficar nervoso não vai adiantar; é melhor manter a calma.

D1:

D2:

D3:

\section{$(\ldots)$}

\section{Responda}

Qual dicionário pareceu-lhe ser mais eficaz para a realização desta tarefa?

Justifique a sua resposta.

Sabendo que o D1 foi publicado pela editora Larousse, o D2 pela Michaelis e o D3 pela Ática, e considerando sua resposta anterior, qual critério de escolha utilizaria?

Figura 5 - Tarefa 2 (seleção de trechos). UD Usos do dicionário'(de nossa autoria).

Da mesma forma que na primeira tarefa, o professor começará a segunda tarefa explicando as informações do material de apoio, aprofundando os conceitos intuitivo e sistemático, dessa vez aplicados aos critérios de escolha de dicionários. 
Francis, M.; DuRÃo, A. B. DE A. B.; VAsConcellos, M. L. - Planejamento e proposta de Unidade Didática para o ensino de tradução: usos do dicionário

Dando prosseguimento à atividade, o aluno lerá as instruções e as informações prévias, dentre as quais há alguns comentários quanto à presença e relevância dos falsos amigos nos DB (FrAnCIS; DURÃo 2009: 79-81).

$\mathrm{Na}$ sequência, o aluno comparará as informações lexicográficas oferecidas por três DB (GálVEz 2005: 4-13; Michaelis 2008: 433-448; FLAvián; FERNÁNDEZ 2008: 488-499) para três falsos amigos do português com relação ao espanhol (adiantar, aliás e apurar), traduzirá ao espanhol as frases nas quais estão contextualizados esses falsos amigos e avaliará quais informações microestruturais ofereceram maior auxílio para o bom andamento da tarefa. Por último, responderá às perguntas que sintetizam os resultados do experimento e lerá suas respostas, comparando-as com as dos colegas, sob a mediação do professor.

A avaliação resultará da realização da tarefa, ou seja, do preenchimento da ficha e da participação oral na contribuição da experiência de cada aluno na atividade proposta.

\subsection{Tarefa 3 - Estratégias para o uso de dicionários em traduções}

Essa tarefa tem por objetivo que o aluno adquira estratégias de uso de diferentes dicionários em situações específicas de tradução. Os elementos constitutivos de sua estrutura são:

(1) Material de apoio;

(2) Ficha 5. Mesa à chinesa;

(3) Ficha 6. Diplomado de repostería.

Na Figura 5 apresenta-se o material de apoio oferecido ao aluno para a realização da tarefa. 
Francis, M.; Durão, A. B. de A. B.; VAsconcellos, M. L. - Planejamento e proposta de Unidade Didática para o ensino de tradução: usos do dicionário

Tarefa 3: ESTRATÉGIAS PARA O USO DE DICIONÁRIOS EM TRADUÇÕES

\begin{tabular}{l} 
Material de apoio: Estratégias para o uso de dicionários em traduções \\
\hline Cada classe de dicionário demanda estratégias de uso adequadas para tornar a consulta dinâmica e eficaz (respeitadas as \\
limitações próprias dessas obras de consulta). O ideal é possuir diversos dicionários sempre à mão, e utilizá-los de forma \\
complementaria, juntamente com outras documentações e ferramentas de consulta. Nesse momento, deteremo-nos \\
apenas em alguns desses dicionários por sua aplicabilidade a um tipo específico de texto descritivo: o folheto. \\
Textos da natureza dos folhetos demandam uma atenção redobrada por parte do tradutor (e tempo), pois muitas das \\
informações neles presentes encontram-se num contexto de uso estreito e limitado, podendo conter listas, tabelas ou \\
similares. Por outro lado, essas informações pertencem, na maioria das vezes, a um mesmo campo semântico (assunto, \\
tema). \\
No caso da língua espanhola, outra dificuldade consiste na grande quantidade de variantes linguísticas existentes, \\
tornando a tarefa da tradução mais complexa. Para esses casos, o uso metódico de dicionários especiais pode amenizar \\
consideravelmente as dificuldades do trabalho.
\end{tabular}

Figura 6 - UD Usos do dicionário’(de nossa autoria).

Como aconteceu nas tarefas anteriores, o professor deverá comentar as informações do material de apoio, as quais apontam para a utilidade de certo tipo de dicionários na tradução de um gênero textual específico, o folheto. Os alunos já conhecem algumas tipologias de dicionários expostas na primeira tarefa e, nessa fase, terão a oportunidade de avaliar em que momentos esses dicionários, um visual e o outro de variantes léxicas, podem ser mais úteis.

Nessa tarefa, cada ficha contém um texto extraído e adaptado da internet, um em português e outro em espanhol, bem como folhas de auxílio, que consistem em ilustrações de fragmentos de dicionários para a consulta do aluno com um breve questionário ao final.

Após ler as instruções, e segundo as orientações nelas explicitadas, cada aluno iniciará a leitura do texto da Ficha 5 (exposto, a seguir, na Figura 6) destacando as palavras que considerar de difícil tradução. 
Francis, M.; DuRão, A. B. DE A. B.; VAsconcellos, M. L. - Planejamento e proposta de Unidade Didática para o ensino de tradução: usos do dicionário

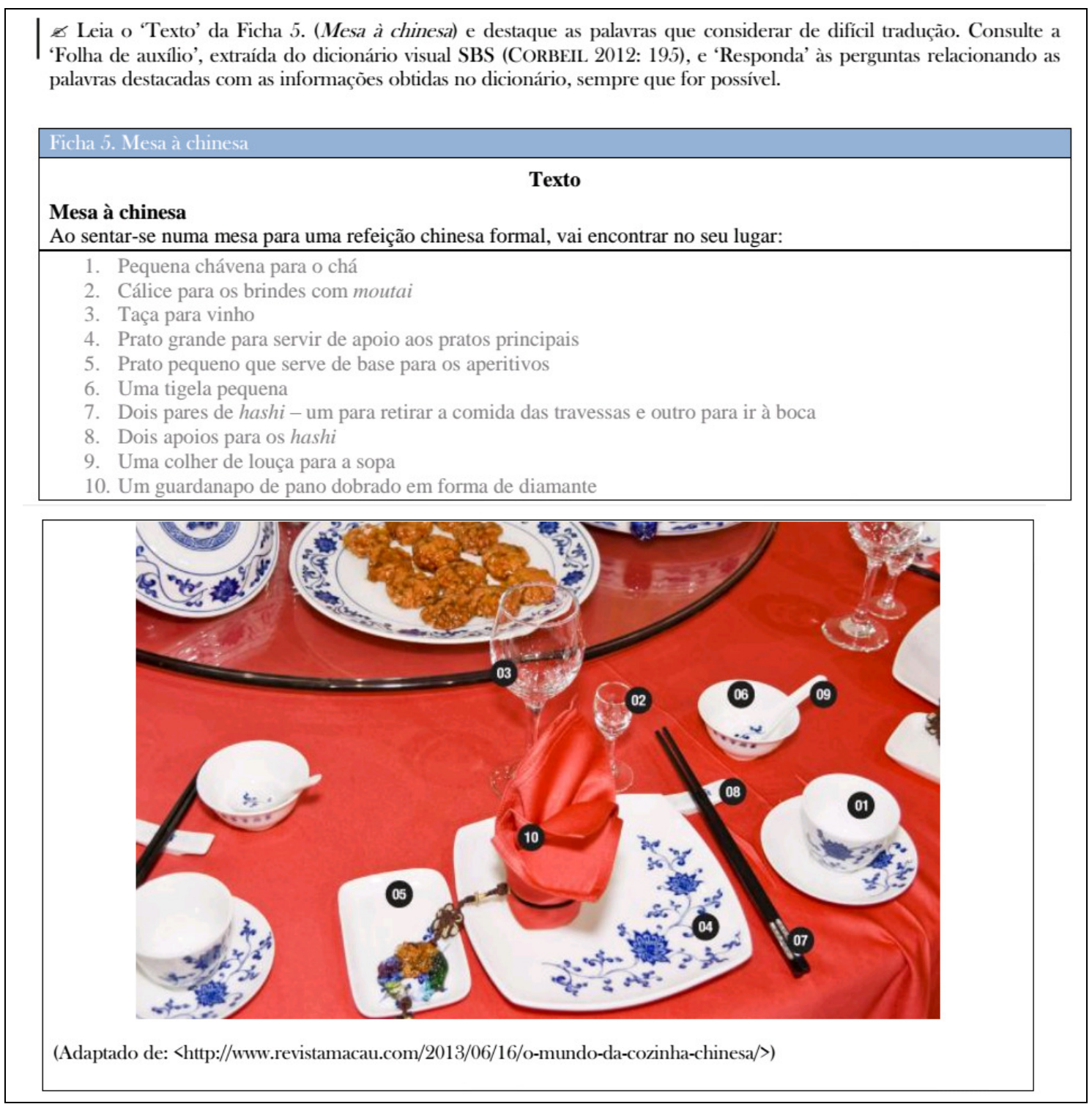

Figura 7 - Texto da Ficha 5. UD Usos do dicionário'(de nossa autoria).

$\mathrm{Na}$ sequência, consultará a folha de auxílio com informações e ilustrações extraídas do dicionário de Corbeil (2012: 195), preencherá a ficha, respondendo a perguntas sobre a utilidade dessas informações e lerá suas respostas a fim de integrar seus conhecimentos e percepções aos dos colegas. Essa fase da tarefa expõe-se a seguir, na Figura 7. 
Francis, M.; Durão, A. B. de A. B.; VAsconcellos, M. L. - Planejamento e proposta de Unidade Didática para o ensino de tradução: usos do dicionário

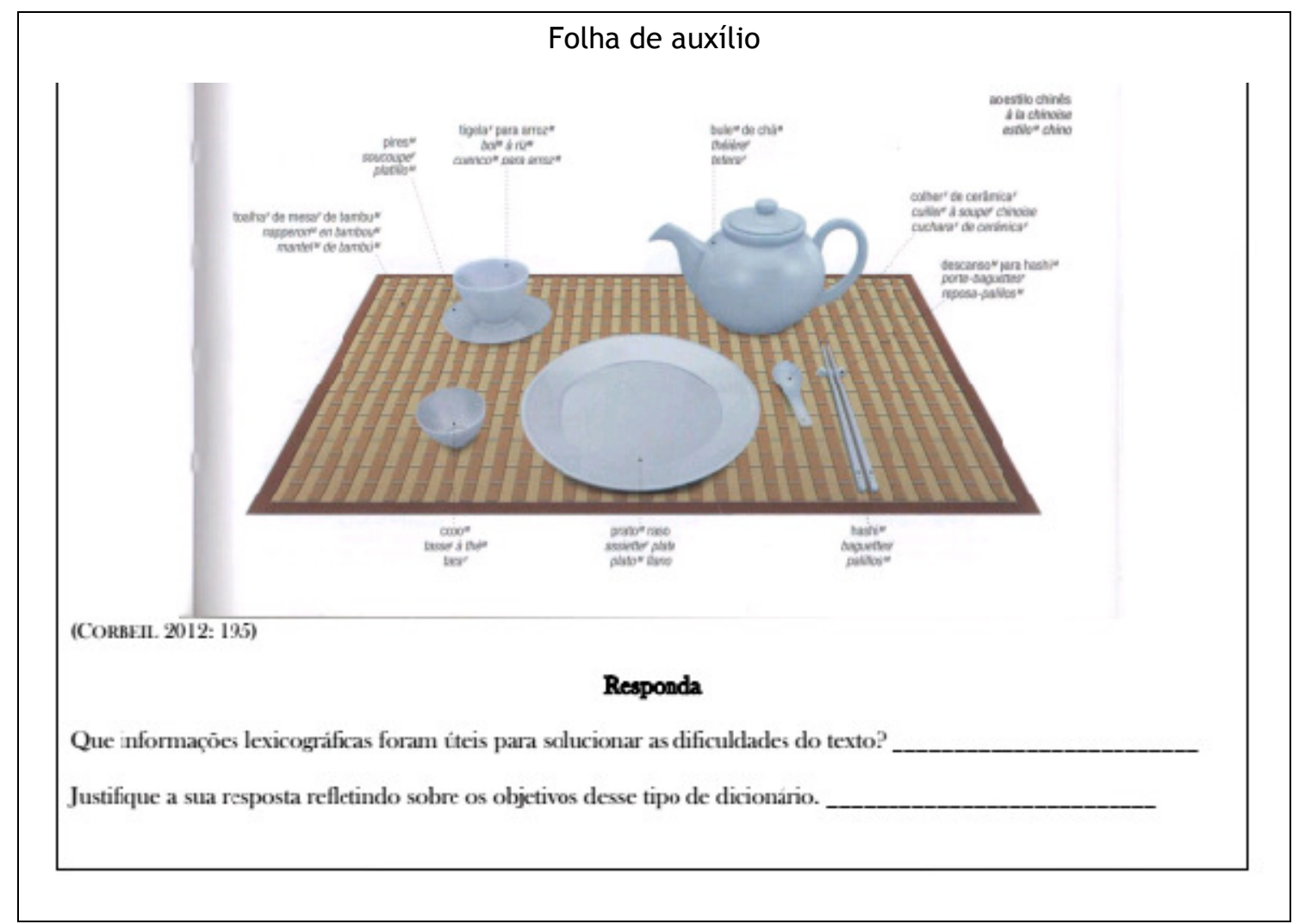

Figura 8 - Folha de auxílio e questionário da Ficha 5. UD Usos do dicionário (de nossa autoria).

O preenchimento da Ficha 6 parte dos mesmos princípios seguidos na ficha anterior, com as diferenças de que se trata de um texto redigido em espanhol e de que as folhas de auxílio foram extraídas do dicionário de Molero (2003: 22-25), uma obra que apresenta, de modo contrastivo e organizadas por assuntos, as variantes linguísticas do espanhol.

Para avaliar o desempenho dos alunos, o professor considerará a realização da tarefa mediante o preenchimento das fichas e pela participação oral em aula. 
Francis, M.; Durão, A. B. De A. B.; Vasconcellos, M. L. - Planejamento e proposta de Unidade Didática para o ensino de tradução: usos do dicionário

\subsection{Tarefa final - Uso de dicionários na tradução direta (espanhol-português)}

O objetivo da tarefa final é promover a tradução direta de um texto real extraído da internet, embora adaptado, a fim de avaliar, de forma global e prática, a apreensão dos conteúdos trabalhados nas tarefas anteriormente referidas.

Essa tarefa é formada por:

(1) Material de apoio;

(2) Texto: Ensillar un caballo;

(3) Protocolo de uso.

Para a tradução do texto poderão ser utilizados quantos dicionários se considerem necessários. Na Figura 8 expõe-se a tarefa final elaborada para essa UD, na qual são explicitadas as informações e as instruções necessárias para sua realização.

Tarefa final: USO DE DICIONÁRIOS NA TRADUÇÃO DIRETA (ESPANHOL-PORTUGUÊS)

Material de apoio: Uso de dicionários na tradução direta (espanhol-português)

Para avaliar metodicamente o potencial de ajuda de um dicionário (ou de vários) na tradução de um texto, será de grande utilidade o preenchimento de protocolos de uso. Esses protocolos consistem em pequenas tabelas nas quais os usuários deverão anotar observações sobre os processos de suas consultas aos dicionários que, no caso desta UD,

realiza-se durante o processo de tradução.

\& Traduza o Texto. (Ensillar un caballo) com auxílio dos dicionários que achar conveniente. Durante essa atividade, preencha o 'Protoco de uso' segundo as consultas realizadas aos dicionários para a tradução desse texto. Por último, compartilhe sua experiência com os colegas lendo e debatendo o protocolo. 
Francis, M.; Durão, A. B. De A. B.; VAsconcellos, M. L. - Planejamento e proposta de Unidade Didática para o ensino de tradução: usos do dicionário

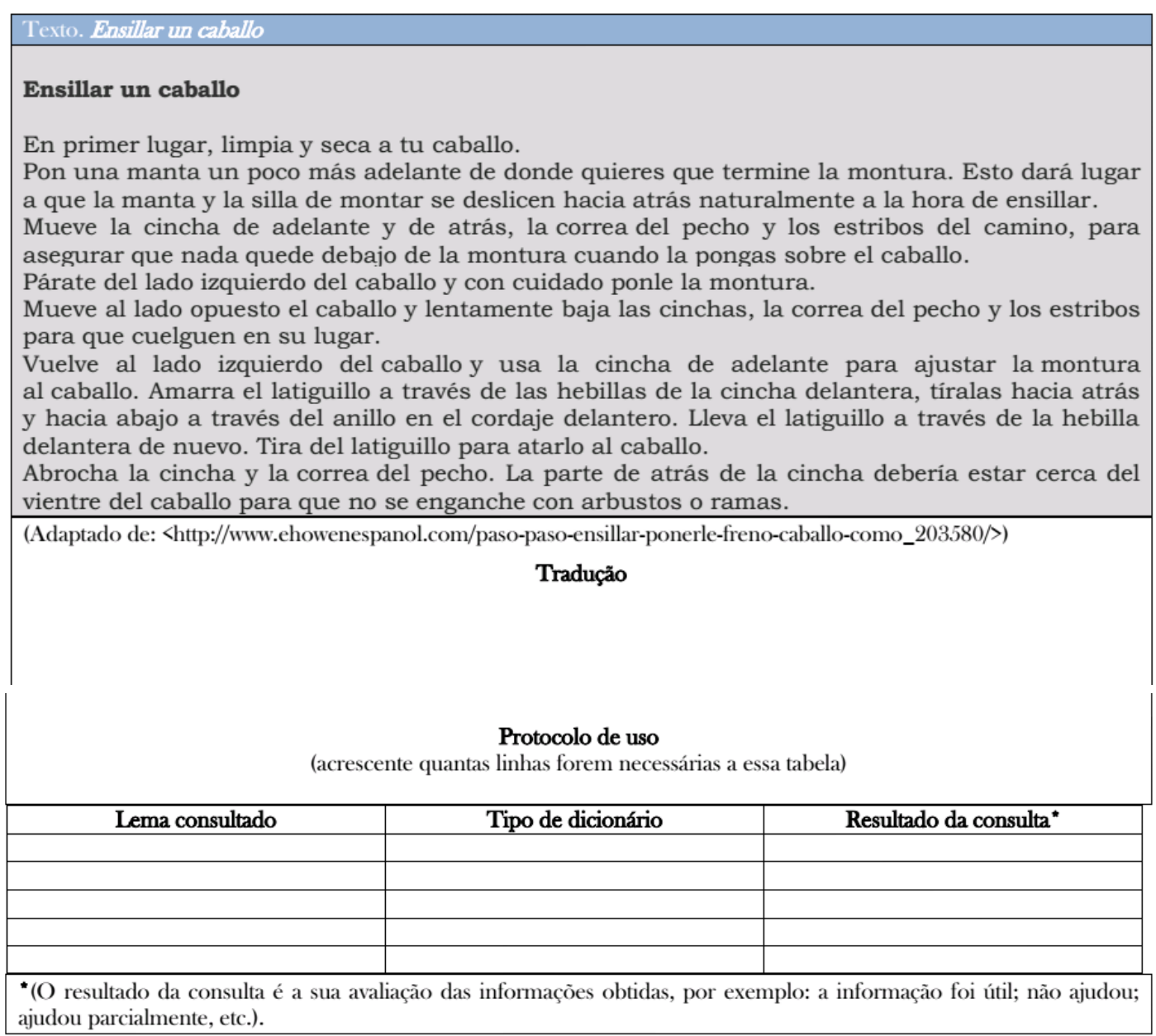

Figura 9 - Tarefa final. UD Usos do dicionário (de nossa autoria).

Uma vez mais, o professor iniciará os comentários sobre o material de apoio, dando ênfase à importância de avaliar as obras lexicográficas em uso de forma metódica para tornar a consulta aos dicionários mais dinâmica e eficaz. O professor explica que o protocolo de uso é uma tabela na qual o tradutor anota o resultado de cada consulta aos dicionários utilizados durante a tradução, avaliando a utilidade das informações oferecidas por cada obra. 0 preenchimento desse protocolo constitui uma ferramenta que permitirá uma visão mais detalhada das obras consultadas. 
Francis, M.; DuRão, A. B. De A. B.; VAsconcellos, M. L. - Planejamento e proposta de Unidade Didática para o ensino de tradução: usos do dicionário

Dando continuidade à tarefa, o aluno lerá as instruções, realizará a tradução com o auxílio dos dicionários escolhidos, preenchendo, na medida em que realizar as consultas, o protocolo de uso.

Como atividade final, promover-se-á um debate no qual os alunos compartilharão suas experiências, lendo e comentando seus protocolos de uso. A avaliação dessa tarefa será efetuada pelo desempenho do aluno na tradução solicitada, o preenchimento do protocolo de uso e a participação oral no debate.

Como informações adicionais, apresentam-se as referências bibliográficas complementares para consulta ao final da unidade.

\section{Considerações finais}

Ao propor a elaboração de uma UD voltada para o desenvolvimento da subcompetência instrumental, a ser desenvolvida no contexto da formação de tradutores, com ênfase na aquisição da competência no uso de dicionários, surgiram algumas dificuldades provenientes de incertezas quanto aos conteúdos a serem trabalhados, ao tipo de tarefas a serem propostas e à sua exequibilidade. Tais inquietações foram trabalhadas durante o processo de criação e reelaboração das tarefas aqui apresentadas, as quais foram pautadas nos objetivos que deveriam ser atingidos, numa constante busca do aperfeiçoamento. Reconhecemos que o trabalho não está concluído, ainda mais por se tratar de uma proposta elaborada para uma realidade pedagógica imaginária, embora exequível. Além disso, considerando-se os princípios pedagógicos informando o desenho da atividade, sua versão final estará sempre em desenvolvimento e aperfeiçoamento, uma vez que a cada utilização do material em sala de aula, aperfeiçoamentos ocorrerão como decorrência da resposta dos alunos, em uma dinâmica integradora e flexível. 
Francis, M.; DuRÃo, A. B. DE A. B.; VAsconcellos, M. L. - Planejamento e proposta de Unidade Didática para o ensino de tradução: usos do dicionário

Estamos cientes de que o uso da UD, num contexto de aprendizagem real, provocará novas reformulações, pois as realidades da sala de aula exigem adaptações constantes às necessidades dos aprendizes e também dos docentes. Os ajustes poderão ser necessários, também, ao se pensar no aproveitamento do trabalho para outras temáticas. Obteve-se, entretanto, um desenho que embora não definitivo, parece-nos atender aos objetivos propostos.

Quanto ao uso da abordagem por tarefas de tradução como metodologia para o ensino dessa atividade e, no caso em particular, também do ensino do uso de dicionários, são perceptíveis algumas vantagens desse método, tais como:

(1) desenvolver no aluno uma visão teórico-prática dos conteúdos, mediante a realização e a reflexão sobre as tarefas;

(2) propor ao aluno situações reais ou, ao menos, factíveis de acontecer, que o insiram no âmbito do trabalho que irá desenvolver como profissional;

(3) dar voz ao aluno para que colabore na resolução das problemáticas propostas, desenvolvendo, assim, diversas inteligências e habilidades;

(4) oferecer um espaço de interação, que contribua com a formação do conhecimento e o desenvolvimento da competência tradutória e de consulta aos dicionários.

Por último, cabe destacar que a construção de uma UD é muito mais do que a mera vivência de um processo criativo. Trata-se da programação de atividades que envolvem teorias quanto ao ensino e a aprendizagem, pensadas, refletidas, avaliadas e reavaliadas, e que, portanto, consiste em uma questão de escolhas, a fim de direcionar, da melhor maneira possível, os passos dos aprendizes em busca do conhecimento. 
Francis, M.; DuRão, A. B. DE A. B.; VAsconcellos, M. L. - Planejamento e proposta de Unidade Didática para o ensino de tradução: usos do dicionário

\section{Referências Bibliográficas}

BeVILACQUA, C. R. Lexicografia bilíngue: aspectos teóricos e reflexões sobre dicionários bilíngues português-espanhol e espanhol-português. In: RoTTAVA, Lucia; SANTOS, Sulany Silveira dos. (Org.). Ensino e aprendizagem de línguas: Línguas estrangeiras. Coleção linguagens. Ijuí: Unijuí, 2006: 107-138.

CoRBEIL, J-C. (Dir.). Dicionário visual SBS Português-Francês-Espanhol. São Paulo: HUB, 2012.

Duran, M. S.; XataRa, C. M. Lexicografia Pedagógica: atores e interfases. D.E.L.T.A., n. 23, v. 2, São Paulo, 2007: 203-222.

FLAVIÁN, E.; FeRnÁNDEZ, G. E. Minidicionário espanhol-português portuguêsespanhol. 18 . ed. São Paulo: Ática, 2008.

Francis, M.; DURão, A. B. de A. B. Uma reflexão sobre o tratamento dado aos falsos amigos do par de línguas português-espanhol em dicionários bilíngues gerais e em dicionários de falsos amigos. In: DURão, A. B. de A. B. (Org.). Por uma lexicografia bilíngue contrastiva. Londrina: UEL, 2009: 79-97.

GÁlvEZ, J. A. (Coord.). Dicionário larousse espanhol-português, portuguêsespanhol: Mini. São Paulo: Larousse do Brasil, 2005.

HURTADO ALBIR, A. Aprender a traducir del francés al español: competencias y tareas para la iniciación a la traducción. Serie Aprender a traducir. Madrid/Castellón: Edelsa, Universitat Jaume I - Servicio de Publicaciones, 2015.

- Enseñar a traducir: Metodología en la formación de traductores e intérpretes. Madrid: Edelsa, 1999.

A aquisição da competência tradutória: Aspectos teóricos e didáticos. In: Pagano, A.; Magalhães, C.; Alves, F. (Orgs.). Competência em tradução: Cognição e discurso. Belo Horizonte: Editora UFMG, 2005: 19-57.

KELLY, D. A. A Handbook for Translator Trainers. Manchester, UK: St. Jerome Publishing, 2005.

- Un modelo de competencia traductora: bases para el diseño curricular. In: Puentes, Granada, n. 1, 2002: 9-20.

KIRALY, D. A Social Constructivist Approach to Translator Education: Empowerment from Theory Practice. Manchester/Northampton: St. Jerome publishing, 2000.

KRIEGER, M. da G. Tipologias de dicionários: Registros de léxico, princípios e tecnologias. Calidoscópio, v. 4, n. 3, São Leopoldo, pp.141-147, 2006. 
Francis, M.; DuRÃo, A. B. DE A. B.; VAsconcellos, M. L. - Planejamento e proposta de Unidade Didática para o ensino de tradução: usos do dicionário

MICHAELIS: Dicionário escolar espanhol. $2^{\mathrm{a}}$. ed. São Paulo: Melhoramentos, 2008.

MOLeRo, A. El español de España y el español de América: Vocabulario comparado. Madrid: SM, 2003.

PACTE. Bulding a translation competence model. In: ALVES, F. (Ed.). Triangulating translation: perspectives in process oriented research. Amsterdam: John Benjamins, 2003: 43-66.

Real ACAdemia Española. Diccionario de la lengua española. 22. ${ }^{a}$ Ed. Disponível em: <http://lema.rae.es/drae/?val=abolengo> Acesso em: jun. 2014.

SaRgentim, H. Dicionário de idéias afins. São Paulo: Instituto Brasileiro de Edições Pedagógicas, $\mathrm{n} / \mathrm{d}$.

WeLKER, H. A. Dicionários: Uma pequena introdução à lexicografia. Brasília: Thesaurus, 2004.

- O uso de dicionários: Panorama geral das pesquisas empíricas. Brasília: Thesaurus, 2006.

WERNER, R. El diccionario bilingüe y la enseñanza del español como lengua extranjera. Revista Hispanorama Literario, n. 110, [S.l.], pp. 75-84, 2005. 